\title{
Museus e projetos culturais: um estudo sobre a aderência de indicadores de desempenho à função social da instituição
}

\author{
Museos y proyectos culturales: um estudio sobre los indicadores de \\ desempeño de la adhesión a la función social de la institución
}

\section{Museums and cultural projects: a study on the performance indicators of adherence to the social function of the institution}

\author{
Elizabete de Castro Mendonça ${ }^{\mathrm{i}}$ \\ Luis Antônio do Nascimento Necoii \\ Nilcemar Nogueiraiii
}

Palavras chave:

Política Pública para área de Cultura

Gestão Cultural

Museu

Indicadores de

desempenho

Centro Cultural Cartola / Museu do Samba Carioca

\section{Resumo:}

Muitos dos editais lançados, no Brasil, exigem vinculação entre preservação de bens culturais e indicadores de desempenho alinhados a metas que visam à gestão e sustentabilidade. No caso dos museus, compreendidos nas atuais políticas públicas como instituições com potencialidades de geração de renda, um dos debates recai sobre se existe e quais as possibilidades de sua total sustentabilidade sem afastar sua função de contribuir para o desenvolvimento sociocultural e econômico da comunidade do entorno. Nossa proposta é analisar potencialidades e dificuldades encontradas pelo Centro Cultural Cartola/ Museu do Samba Carioca para equalizar sua missão institucional, o atendimento às exigências para aprovação de projetos culturais e a comprovação das metas e indicadores alcançados, visando explicitar: 1. se os editais na prática aplicam as propostas encaminhadas pelas Políticas Públicas setoriais de Museu e de Patrimônio Imaterial que se propõem a legitimar as demandas das comunidades; 2. se a configuração dos indicadores de desempenho apresentados nos editais é alinhada à meta de retorno social de interesse da comunidade de sambistas e se reflete os resultados socioculturais e econômicos alcançados pelos projetos. Cientes de atualmente os editais são uma das principais fontes de recurso, analisar e explicitar tais questões é um fator relevante podendo contribuir para a democratização e valorização de conhecimentos culturais. 


\section{Resumen:}

Muchos de los edictos lanzados en Brasil requieren conexión entre la preservación de los indicadores culturales y de desempeño alineados con las metas orientadas a la gestión y la sostenibilidad. En el caso de los museos, entendida en las políticas e instituciones con potencial de generación de ingresos públicos actuales, uno de los debates recae en si y las posibilidades de su sostenibilidad total sin alienar a su función de contribuir al desarrollo socio-cultural y económico de la comunidad que la rodea. Nuestro objetivo es analizar las dificultades potenciales y encontradas por el Centro Cultural Cartola / Samba Carioca Museo de igualar su misión institucional, el cumplimiento de los requisitos para la aprobación de proyectos culturales y prueba de metas e indicadores obtenidos con el fin de explicar: 1. si en los edictos practicar aplicar las propuestas remitidas por las políticas públicas sectoriales y Museo del Patrimonio Inmaterial que pretenden legitimar las demandas de las comunidades; 2. si el ajuste de indicadores de resultados que se presentan en los avisos se alinea con el objetivo de rentabilidad social de interés sambistas comunidad y refleja los resultados socio-culturales y económicos alcanzados por los proyectos. Consciente actualmente los edictos son una de las principales fuentes de financiación, analizan y explican estas cuestiones es un factor que puede contribuir a la democratización y la mejora de los conocimientos culturales.

\section{Palabras clave:}

Políticas Públicas para el área de Cultura

Gestión cultural

Museo

Indicadores de desempeño

Centro Cultural Cartola / Samba Carioca Museo

\section{Keywords:}

Public Policy for Culture area

Cultural management

Museum

Performance indicators

Cultural Center Cartola / Samba Carioca Museum

\section{Abstract:}

Many of the edicts launched in Brazil require connection between preservation of cultural heritage and performance indicators aligned to targets aimed at management and sustainability. In the case of museums, understood in current public policies as institutions with income-generating potential, one of the debates lies with whether there and the possibilities of its total sustainability without alienating its function of contributing to the socio-cultural and economic development of the surrounding community . Our goal is to analyze potential and difficulties encountered by the Cultural Center Cartola / Samba Carioca Museum to equalize its institutional mission, compliance with the requirements for approval of cultural projects and proof of achieved targets and indicators in order to explain: 1. if in edicts practice apply the proposals forwarded by the sectoral public policies Museum and Intangible Heritage that purport to legitimize the demands of communities; 2 . if the setting of performance indicators presented in notices is aligned with the social return target of interest sambistas community and reflects the socio-cultural and economic results achieved by the projects. Aware currently the edicts are a major funding sources, analyze and explain these issues is a factor which may contribute to the democratization and enhancement of cultural knowledge. 


\section{Museus e projetos culturais: um estudo sobre a aderência de indicadores de desempenho à função social da instituição}

\section{Introdução}

Na década de 1990, especialmente nos anos 2000, as Políticas Públicas vinculadas à área da cultura começaram a adquirir novos contornos, após mais de uma década sem ou com pouco investimento, ganhando fôlego no governo do Presidente Fernando Henrique Cardoso e passando a adquirir maiores impulsos, mediante construção de uma agenda política criada, em 2003, no primeiro mandato do Presidente Luis Inácio Lula da Silva (CALABRE, 2009). Nesta corrente o Ministério da Cultura passou a estruturar Políticas Culturais respondendo às três dimensões da cultura que guiaria o Plano Nacional de Cultural (PNC)iv, a saber: a da cidadania, com a garantia do direito de acesso; a do simbólico, que estimula o processo criativo e imaginativo; e a do econômico, que estimula o desenvolvimento socioeconômico local e regional.

Neste contexto, um marco representativo para a política pública na área cultural foi a inclusão do parágrafo $3^{\circ}$ no artigo 215 da Constituição Federal de 1988, instituindo o Plano Nacional de Cultura, mediante a aprovação da Emenda Constitucional $48 / 2005$. O texto legal passa a estabelecer "o Plano Nacional de Cultura, de duração plurianual, visando ao desenvolvimento cultural do País e à integração das ações do poder público" (BRASIL, Art. 215 , parágrafo $3^{\circ}$ ).

A cultura passou a ser considerada um campo em expansão e adquiriu maior importância econômica com linhas de financiamentos patrocinadas pela esfe- ra pública e por instituições privadas. De acordo com o Instituto Brasileiro de Geografia e Estatística - IBGE (2007), o setor cultural apresentou um desenvolvimento de mais de $500 \%$ em dez anos, gerando cerca de 1,8 milhão de empregos. Dados do Ministério da Cultura indicam que a cada ano é estimado um aumento maior. Segundo Instituto Brasileiro de Museus IBRAM (2014, p. 18)

Estudos recentes indicam que as atividades de criação, produção, difusão e consumo de bens e serviços culturais representam o setor mais dinâmico da economia mundial e registraram um crescimento médio de $6,3 \%$ ao ano nos primeiros anos da década passada, enquanto o conjunto da economia cresceu a 5,7\% (UNCTAD, 2010). Estimativas do Banco Mundial situam a Cadeia Produtiva da Cultura como responsável por $7 \%$ do Produto Interno Bruto (PIB) do planeta em 2008. Apesar de não haver informações totalmente sistematizadas sobre o seu impacto na economia brasileira, a cultura é responsável por aproximadamente $4 \%$ do PIB anual e é reconhecida como um eixo estratégico de desenvolvimento socioeconômico pelo MinC.

Dentro dessa perspectiva, no cenário brasileiro, foram criadas ou ampliadas edições de editais patrocinados por instituições ${ }^{\vee}$ públicas e privadas para contratação de projetos. Estes editais, de acordo com a instituição que os promove, são denominados: chamadas públicas, seleções públicas, entre outras. O fundamental é que se caracterizam como processos seletivos públicos que buscam oferecer a todos os interessados a chance de concorrer ao patrocínio com igualdade de condições. No entanto, como demonstram estudos, a exemplo de Hanson (2006) e Thiry-Cherques (2008), esta igualdade de condições de fato não existe. Thiry-Cherques (2008, 
p. 14) afirma que "[...] o desconhecimento das técnicas mais elementares de gestão tem condenado ao esquecimento excelentes ideias, movimentos generosos em favor da cultura"vi. Este desconhecimento deve-se a diferentes fatores. Na área da cultura, por exemplo, a dificuldade de grupos ou indivíduos detentores de referências culturais ou até mesmo de profissionais de instituições culturais dominarem a linguagem e estruturação necessária para a configuração de um projeto alinhado às metas e indicadores de desempenho definidos nos editais ${ }^{\text {vii }}$.

Segundo Mendonça e Neco (2013, p. 107-108), apesar dos baixos recursos viii destinados historicamente para a área da cultura, ocorreu o crescimento no número de projetos considerados aptos pelo Ministério da Cultura à capacitação de recursos, bem como o número de projetos que efetivamente conseguiram captar recursos via Mecenatoix e Fundo Nacional de Cultura $(\mathrm{FNC})^{x}$. Para os mesmos autores, entre os anos de 1993 e 2011, os números crescentes de investimento devem-se ao

novo enfoque dado às políticas públicas para a área da cultura na década de 1990, com base na promulgação da Lei Federal de Incentivo à Cultura (8.313/91) que instituiu, por meio do Programa Nacional de Apoio à Cultura (Pronac), os mecanismos do Fundo Nacional de Cultural (FNC), do Mecenato e do Fundo de Investimento Cultural e Artístico (Ficart) ${ }^{x i}$. Na prática, $85 \%$ desses projetos passaram a ser financiados via Mecenato, dos quais $83,9 \%$ decorrentes de renúncia fiscal concedida pelo governo federal. (Tradução nossa)

Em nível estadual, no Rio de Janeiro, foi criada, em 1992, a Lei Estadual de Incentivo à Cultura - um mecanismo de fomento que dispõe sobre concessão de benefício fiscal para realização de projetos culturais, permitindo as empresas, contribuintes de ICMS patrocinarem a produção cultural utilizando o incentivo fiscal concedido pelo Estado.

Com base nessas premissas, este estudo analisará as potencialidades e dificuldades encontradas pelo Centro Cultural Cartola/Museu do Samba Carioca para equalizar sua missão institucional, o atendimento às exigências para aprovação de projetos culturais e a comprovação das metas e indicadores de desempenho alcançados, visando explicitar: 1 . se os editais na prática aplicam as propostas encaminhadas pelas Políticas Públicas setoriais de Museu e de Patrimônio Imaterial que se propõem a legitimar as demandas das comunidades; 2. se a configuração dos indicadores de desempenho apresentados nos editais é alinhada à meta de retorno social de interesse da comunidade de sambistas e se reflete os resultados socioculturais e econômicos alcançados pelos projetos.

A metodologia utilizada nesta pesquisa classifica-se como descritiva, que tem por objetivo a descrição das características de determinada população (GIL, 2010). Em relação aos métodos empregados, a pesquisa possui caráter qualitativo, com coleta de dados bibliográficos e documentais (GIL, 2010 ; MARCONI; LAKATOS, 2011).

\section{O Centro Cultural Cartola}

Fundado em 2001, o Centro Cultural Cartola (CCC) é uma organização sem fins lucrativos, criada com o objetivo inicial de motivar os jovens moradores do Morro da Mangueira e adjacências (no município do Rio de Janeiro, Brasil) a identificar valores culturais das comunidades a que pertencem, tendo como base desse empreendimento a vasta obra de Angenor de Oliveira, o Cartola -sambista, compositor 
e fundador da Escola de Samba Estação Primeira de Mangueira.

Reconhecido como Ponto de Culturaxii em 2005, e tendo sido proponente da candidatura do samba cariocaxiii a patrimônio cultural imaterial, o CCC passou, a partir de janeiro de 2009 , com o apoio do Instituto do Patrimônio Histórico e Artístico Nacional (IPHAN), a Pontão de Cultura Memória do Samba Carioca .No âmbito das ações do Pontão foi implantado um Centro de Referência de Pesquisa e Documentação do Samba do Rio de Janeiro, o que ampliou a ação do Centro, trabalhando a preservação da memória do samba carioca, com o resgate de suas referências culturais, em suas mais diversas formas de manifestação presentes nas rodas de samba, nas quadras das escolas de samba e em outras agremiações carnavalescas, nos terreiros, e na atuação dos seus atores sociais, constituindo-se assim parte integrante na execução do plano de salvaguarda das Matrizes do Samba no Rio de Janeiro.Seguindo as recomendações do IPHAN, além de dar condições para criação, produção, apresentação e difusão das matrizes do samba - música e dança -, outras ações foram dirigidas para a pesquisa e capacitação de recursos humanos dentro das comunidades de sambistas. Com base nestas premissas, encontros realizados com as bases sociais geraram recomendações de proteção para aos bens, descritas no Dossiê e ratificada no Parecer da relatora do Conselho Consultivo do Iphan ${ }^{\times v}$.

1. Ampla pesquisa e documentação, tanto dos três tipos de samba enquanto formas de expressão artística, como de sua história e da biografia de seus principais representantes. E em especial o "levantamento da produção musical, com a recuperação (e gravação) de letras e melodias de partidos-altos, sambas de terreiro e sambas-enredo, visto que parte significativa da produ- ção das comunidades de sambistas, principalmente a mais afeita às formas tradicionais, de caráter não comercial, não foi registrada" (DOSSIÊ, p. 120).

2. Formação de pesquisadores dentro das diversas comunidades de sambistas, de modo a que possam se tornar os agentes da salvaguarda de seu patrimônio cultural.

3. Promoção e documentação de encontros entre sambistas mais velhos e as novas gerações, visando à transmissão de conhecimentos, pois "a prática é a primeira escola do samba" (DOSSIÊ, p. 121).

4. Criação de centros de memória e referência do samba dentro das comunidades ou na Cidade do Samba, de modo a "facilitar aos sambistas o acesso aos estudos, investigações acadêmicas e acervos de imagem e de som sobre o samba do Rio" (DOSSIÊ, p. 122).

Segundo Nogueira (2014, p. 34), tanto a idealização do CCC quanto as ações propostas no Plano de Salvaguarda das Matrizes do Samba no Rio de Janeiro tiveram como base o inconformismo de sambistas com o descaso com a memória do samba, somado a outros fatores como a falta de protagonismo social, a descaracterização imposta pela indústria cultural e pelos efeitos da globalização, que submeteram a cultura de resistência à perda de suas características fundamentais, afetando seus núcleos e enfraquecendo suas referências. Ainda segundo a autora:

$\mathrm{Na}$ circulação global da cultura de massa, ou talvez por causa dela, emergiu uma diferença local, com administração e investimento transnacional, cujos efeitos o CCC sabe dispor a seu favor, de modo direto e objetivo. No Centro Cultural, arte e cultura não são artefatos meramente assistenciais, pois que o beneficio vem com a consciência de que, ao longo da his- 
tória, houve a negação, pelo sistema sociopolítico e cultural, dos valores ancestrais das comunidades excluídas, em geral composta por pobres, negros e, no caso do Brasil, por outros grupos sociais, como, por exemplo, os indígenas, os nordestinos e os analfabetos.

Havia ainda a preocupação em oferecer acesso à diversidade, sempre cuidando para que não houvesse, e nem haja perda da referência identitária. $O$ Centro Cultural Cartola se constituiu em um difusor da identidade cultural como referência construída tanto para os grupos culturais quanto para a sociedade, fugindo ao sentido reducionista e estático dessa representação. Desde 2013, o CCC encontra-se em processo de estudo para sua reconfiguração, inclusive com mudança de nome. Sua meta é se configurar como Museu do Samba Carioca, pois desde 2005 (com a primeira exposição permanente) fomentou o surgimento de um espaço de musealização e de memória social pararevelar a história dosamba como a "expressão cultural" que melhor representa a alma brasileira em sua totalidade coletiva. Segundo Nogueira $(2014$, p. 35), esta "alma, que, vinda do passado, desemboca no presente e se projeta no futuro. O samba brasileiro, um processo cultural, sempre em transformação tem a manutenção da tradição por desafio maior". Como instrumento para a manutenção da tradição está a musealização, utilizada como estratégia de preservação, objetivando não apenas garantir integridade física de coleções, mas também promover ações de pesquisa e documentação voltadas à produção, registro e disseminação de informações relacionadas ao samba, com vistas a fazer conhecê-lo nas suas características fundamentais e garantir a transmissão de sua essência a gerações futuras, propiciando assim a musealização a partir dos próprios atores sociais intimamente ligados ao bem cultural.

\section{Projetos do Centro Cultural Cartola submetidos a editais públicos}

Ao longo de seus 14 anos de existência o Centro Cultural Cartola para manutenção de suas ações celebrou convênios, concorreu a editais e prêmios e recebeu doações. Os recursos derivados de convênios, editais e prêmios foram subsidiados por instituições como Ministério da Cultura (por meio de suas vinculadas: Coordenadoria Geral de Execução Orçamentária, Financeira, Instituto do Patrimônio Histórico e Artístico Nacional, Fundação Cultural Palmares e Instituto Brasileiro de Museus), Ministério da Saúde, Secretaria Especial de Políticas de Promoção da Igualdade Racial (SEPPIR), Secretaria de Políticas para as Mulheres, Petrobras xvi, Governo do Estado do Rio de Janeiro (por meio de suas vinculadas: Superintendência de Desporto do Estado do Rio de Janeiro, Secretaria de Esporte e Lazer, Secretaria de Assistência Social e Direitos Humanos, Secretaria de Cultura), Prefeitura do Rio de Janeiro (por meio da Secretaria de Cultura), Organização das Nações Unidas para a Educação, a Ciência e a Cultura - UNESCO (Criança Esperança). Parte deste recurso vindo do Fundo Nacional de Cultura (FNC) e do Imposto sobre Circulação de Mercadorias e Serviços (ICMS).

Para esta pesquisa o escopo de análise ficou restrito a uma parcela dos projetos encaminhados para a viabilização de recursos para os quais até o ano de 2014 o CCC/RJ foi habilitado e, efetivamente, executou, concluiu suas ações e realizou a prestação de contas.

A pesquisa foi realizada sobre dados disponibilizados no Portal da Transparênciaxvii, no Sistema de Apoio às Leis de Incentivo à Cultura (especificamente no Sa-

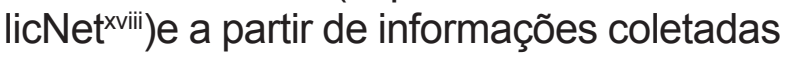
no CCC/RJ. Os dados levantados do Portal da Transparência foram coletados em março de 2015 e são apresentados na tabela 1. 


\section{Tabela 1}

\begin{tabular}{|c|c|c|c|c|c|c|c|c|c|}
\hline \multicolumn{2}{|c|}{ Orgão } & \multirow{2}{*}{$\begin{array}{c}\text { Convênio } \\
\mathbf{n}^{\circ}\end{array}$} & \multicolumn{3}{|c|}{ Valorem RS } & \multirow{2}{*}{$\%$} & \multirow{2}{*}{ Metas } & \multicolumn{2}{|c|}{ Vigência } \\
\hline Supe rior & Conce dente & & Recebidos & CCC/RJ & $\begin{array}{c}\text { Totais por } \\
\text { Projetos }\end{array}$ & & & Início & Fim \\
\hline MinC & CGEOF/FNC & 472628 & $400.000,00$ & $100.000,00$ & $500.000,00$ & $22,1 \%$ & Implantação do CCC/RJ & $27 / 12 / 2002$ & $30 / 06 / 2003$ \\
\hline MinC & $\mathrm{CGEOF/FNC}$ & 521901 & $149.992,00$ & $38.000,00$ & $187.992,00$ & $8,3 \%$ & Orquesta de violinos & $22 / 12 / 2004$ & $12 / 04 / 2009$ \\
\hline MinC & IPHAN & 532441 & $200.000,00$ & $50.000,00$ & $250.000,00$ & $11,0 \%$ & $\begin{array}{l}\text { Realizar pesquisa para } \\
\text { instrução do processo de } \\
\text { Registro do Samba Carioca, } \\
\text { Montar banco de dados e } \\
\text { realizar exposição sobre a } \\
\text { trajetória do samba do Rio } \\
\text { de Janeiro }\end{array}$ & $09 / 12 / 2005$ & $30 / 04 / 2007$ \\
\hline MinC & IPHAN & 702627 & $400.000,00$ & $100.000,00$ & $500.000,00$ & $22,1 \%$ & 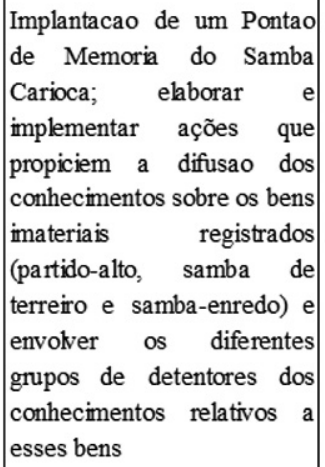 & $31 / 12 / 2008$ & $01 / 02 / 2010$ \\
\hline MinC & IPHAN & 749663 & $400.000,00$ & $100.000,00$ & $500.000,00$ & $22,1 \%$ & $\begin{array}{l}\text { Implantacao da segunda } \\
\text { etapa do projeto Pontao de } \\
\text { Memoria do Samba Carioca. }\end{array}$ & $19 / 11 / 2010$ & $28 / 02 / 2012$ \\
\hline MinC & IPHAN & 763527 & $260.000,00$ & $65.000,00$ & $325.000,00$ & $14,4 \%$ & $\begin{array}{l}\text { Implantacao da terceira } \\
\text { etapa do projeto Pontao de } \\
\text { Memoria do Samba Carioca. }\end{array}$ & $06 / 01 / 2012$ & $06 / 05 / 2013$ \\
\hline \multicolumn{3}{|c|}{ Total de Recursos em RS } & $1.809 .992,00$ & $453.000,00$ & $2.262 .992,00$ & \multicolumn{4}{|l|}{$100,0 \%$} \\
\hline & \multicolumn{9}{|l|}{ Siglas } \\
\hline & $\begin{array}{l}\mathrm{Min} \mathrm{C} \\
\text { IPAHN } \\
\text { CGEOF/FNC }\end{array}$ & $\begin{array}{l}\text { Ministério da } \\
\text { Instituto do } \mathrm{P} \\
\text { Coordenação }\end{array}$ & $\begin{array}{l}\text { Cultura } \\
\text { atrimônio Históric } \\
\text { Geral de Execuçã }\end{array}$ & $\begin{array}{l}\text { e Artistico Nac } \\
\text { Orçamentário e }\end{array}$ & $\begin{array}{l}\text { cional } \\
\text { Financeira/Fund }\end{array}$ & 1o Nacion & al de Cultura & & \\
\hline
\end{tabular}

Fonte: Portal da Transparência, http://www.portaltransparencia.gov.br/5

A tabela 1 apresenta os convênios firmados entre o CCC/RJ e o Governo Federal do Brasil, inclusive, contemplando o primeiro projeto que tinha por objetivo efetivar a implantação do Centro. No total, foram seis convênios iniciados e finalizados, entre os anos de 2002 e 2013, totalizando o montante de $\mathrm{R} \$ 1.809,992,00$ (um miIhão, oitocentos e nove mil, novecentos e noventa e dois reais). Em contrapartida, o $\mathrm{CCC} / \mathrm{RJ}$ aportou aos projetos o valor total de $\mathrm{R} \$ 453.000,00$ (quatrocentos e cinquen- ta e três mil reais). Somados os recursos concedidos pelo Governo Federal com as contrapartidas do CCC/RJ, os projetos totalizaram o montante de $R \$ 2.262 .992,00$ (dois milhões, duzentos e sessenta e dois mil, novecentos e noventa e dois reais).

Analisando a tabela 1, observa-se que $69,6 \%$ (sessenta e nove e seis décimos percentuais) dos recursos foram utilizados em projetos vinculados ao Programa Nacional de Patrimônio Imaterial 
(PNPI), mediado pelo Instituto do Patrimônio Histórico e Artístico Nacional (IPHAN) - instituição que gerencia em nível federal o programa. Os objetivos desses projetos estão voltados ao registro das Matrizes do Samba no Rio de Janeiro como patrimônio imaterial e/ou a processos de salvaguarda deste bem promovendo ações de pesquisa, catalogação, conservação, comunicação e capacitação para gestão.

Dos recursos gerais presentes no Portal da Transparência 8,3\% (oito e três décimos percentuais) foram destinados a ações voltadas à inclusão social, que também corresponde aos objetivos e finalidades do CCC/RJ.

Centro Cultural Cartola alia à sua atuação em defesa da cultura brasileira uma série de iniciativas de cunho social, visando combater a pobreza, a marginalização da população carente, a exclusão social e a falta de esperan- ça no futuro. Em busca de seus ideais, o Centro Cultural Cartola procura atuar junto às parcelas mais desfavorecidas da população, dando especial atenção ao desenvolvimento de crianças e adolescentes, à inserção do jovem na sociedade e ao amparo ao idoso. Tudo isso em torno da cultura e da música brasileiras, importantes instrumentos para a valorização da identidade nacional. (CCC/RJ, 2014 ${ }^{\mathrm{xix}}$ ).

Se considerar que o convênio firmado para implantação do Centro Cultural Cartola, no valor de $\mathrm{R} \$ 500.000,00$ (quinhentos mil reais), teve como meta a reforma do espaço físico do antigo Instituto Brasileiro de Geografia e Estatística (IBGE) cedido para instalação da sede do CCC e, consecutivamente, realização de sua missão institucional, pode-se afirmar que a totalidade de recursos foi destinada aos objetivos propostos pelo CCC/RJ, conforme tabela 2 .

\section{Tabela 2}

\begin{tabular}{|c|c|c|c|c|c|c|}
\hline \multicolumn{2}{|c|}{ Orgão } & \multirow{2}{*}{$\begin{array}{c}\text { Convênio } \\
n^{\circ}\end{array}$} & \multicolumn{3}{|c|}{ Valor em RS } & \multirow{2}{*}{$\%$} \\
\hline Superior & Concedente & & Recebidos & CCC/RJ & $\begin{array}{l}\text { Totais por } \\
\text { Proje tos }\end{array}$ & \\
\hline $\operatorname{MinC}$ & CGEOF/FNC & 521901 & $149.992,00$ & $38.000,00$ & $187.992,00$ & $10,6 \%$ \\
\hline MinC & IPHAN & 532441 & $200.000,00$ & $50.000,00$ & $250.000,00$ & $14,2 \%$ \\
\hline $\mathrm{MinC}$ & IPHAN & 702627 & $400.000,00$ & $100.000,00$ & $500.000,00$ & $28,4 \%$ \\
\hline MinC & IPHAN & 749663 & $400.000,00$ & $100.000,00$ & $500.000,00$ & $28,4 \%$ \\
\hline $\operatorname{MinC}$ & IPHAN & 763527 & $260.000,00$ & $65.000,00$ & $325.000,00$ & $18,4 \%$ \\
\hline \multicolumn{3}{|c|}{ Total de Recursos em RS } & $1.409 .992,00$ & $353.000,00$ & $1.762 .992,00$ & $100,0 \%$ \\
\hline
\end{tabular}

Fonte: Portal da Transparência, http://www.portaltransparencia.gov.br/

O exame da tabela 2 indica que os convênios identificados com metas aderentes aos objetivos do CCC/ RJ foram firmados, majoritariamente $(89,4 \%)$, com o organismo concedente Instituto do Patrimônio Histórico Artístico Nacional (IPHAN), ficando a Coordenação Geral de Execução Orça- mentário e Financeira, que se utilizou do Fundo Nacional de Cultura, com $10,6 \%$ do total de recursos cedidos. Ressalta-se que todos os convênios tiveram como órgão superior de aprovação o Ministério da Cultura, na condição de entidade máxima brasileira com a responsabilidade de promover 
o fomento na esfera cultural, em todo território nacional.

No caso específico do projeto Pontão da Memória do Samba Carioca, os indicadores de acompanhamento estavam atrelados ao desenvolvimento das atividades (cronograma) e relacionavam os indicadores físicos e financeiros a cada uma das fases de execução. Associado à matriz de execução havia um cronograma de desembolso financeiro. Em ambas as situações, observa-se que os indicadores arbitrados privilegiam o acompanhamento quantitativo da execução do projeto.
O Sistema de Apoio às Leis de Incentivo à Cultura (SalicNet) foi a segunda fonte de consulta desta pesquisa, onde foram coletados outros dados sobre recursos captados por meio de projetos. Pelos dados disponibilizados, foram encontrados outros projetos voltados para área da cultura, cujos recursos são oriundos de renúncia fiscal do Governo Federal. Neste modelo de fomento, as empresas beneficiadas pela economia fiscal são obrigadas a aplicar os recursos correspondentes em projetos na área da cultura, por meio de editais. Os dados coletados encontram-se sumarizados na tabela 3 , conforme segue:

\section{Tabela 3}

\begin{tabular}{|c|c|c|c|c|c|c|c|}
\hline \multicolumn{2}{|c|}{ Orgão } & \multirow{2}{*}{$\begin{array}{c}\text { Projeto } \\
n^{\circ}\end{array}$} & \multirow{2}{*}{\begin{tabular}{|c|} 
Valor em RS \\
Captados
\end{tabular}} & \multirow{2}{*}{$\%$} & \multirow{2}{*}{ Metas } & \multirow{2}{*}{\begin{tabular}{|c|} 
Liberação \\
do \\
recurso
\end{tabular}} & \multirow{2}{*}{$\begin{array}{l}\text { Prestração } \\
\text { de contas }\end{array}$} \\
\hline Superior & Concedente & & & & & & \\
\hline $\mathrm{MinC}$ & Petrobrás & 63931 & $198.000,00$ & $11,0 \%$ & $\begin{array}{l}\text { O projeto Orquestra de Violinos prevê a expansão do } \\
\text { universo musical dos ahunos, em especial a formação } \\
\text { de violinistas, para compôr a Orquestra de Violinos, } \\
\text { formação de novos talentos. }\end{array}$ & $20 / 11 / 2006$ & $09 / 03 / 2009$ \\
\hline $\mathrm{MinC}$ & Petrobrás & 78034 & $250.000,00$ & $13,8 \%$ & $\begin{array}{l}\text { Desenvolver programação das atividades da } \\
\text { Orquestra de Violimos, composta de oficinas de } \\
\text { música, em especial a formação de violinistas para } \\
\text { compôr a Orquestra, formação de platéias e } \\
\text { apresentações musicais de todos os gêneros musicais, } \\
\text { inchusive o samba. }\end{array}$ & $19 / 02 / 2009$ & $04 / 04 / 2011$ \\
\hline $\mathrm{MinC}$ & Petrobrás & 90888 & $250.000,00$ & $13,8 \%$ & $\begin{array}{l}\text { O projeto Orquestra de Violinos dá continuidade a } \\
\text { Orquestra prevê a expansão do universo musical dos } \\
\text { ahunos, em especial a formação de violinistas, para } \\
\text { compôr a Orquestra de Violinos, como forma de } \\
\text { propiciar a formação de novos talentos. }\end{array}$ & $23 / 02 / 2010$ & $05 / 05 / 2011$ \\
\hline $\operatorname{MinC}$ & Petrobrás & 101467 & $250.000,00$ & $13,8 \%$ & $\begin{array}{l}\text { O projeto Orquestra de Violinos dá continuidade a } \\
\text { Orquestra prevê a expansão do universo musical dos } \\
\text { ahunos, em especial a formação de violinistas, para } \\
\text { compôr a Orquestra de Violinos, como forma de } \\
\text { propiciar a formação de novos talentos e de phtéias } \\
\text { diferenciadas para a agenda cultural disponibilizada } \\
\text { pela entidade, que passa a envolver na sua } \\
\text { programação outros gêneros musicais, além do } \\
\text { samba. }\end{array}$ & $21 / 02 / 2011$ & $04 / 08 / 2014$ \\
\hline $\mathrm{MinC}$ & Petrobrás & 710615 & $860.000,00$ & $47,6 \%$ & $\begin{array}{l}\text { Realizar o projeto "Centro Cultural Cartola } \\
\text { Adaptação", que consiste na reestruturação e } \\
\text { ampliação de uso do espaço físico, permitindo a } \\
\text { ventilação e instalações de salas de aula do referido } \\
\text { centro, além da implantação do futuro Centro de } \\
\text { Referência da Memória do Samba Carioca. }\end{array}$ & $20 / 01 / 2010$ & $14 / 02 / 2013$ \\
\hline \multicolumn{3}{|c|}{ Total de Recurs os em RS } & $1.808 .000,00$ & \multicolumn{4}{|l|}{$100,0 \%$} \\
\hline \multicolumn{8}{|c|}{ Siglas } \\
\hline & $\begin{array}{l}\text { Min C } \\
\text { Petrobrás }\end{array}$ & \multicolumn{6}{|c|}{$\begin{array}{l}\text { Min istério da Cultura } \\
\text { Petróleo Brasileiro S.A }\end{array}$} \\
\hline
\end{tabular}

Fonte: http://sistemas.cultura.gov.br/salicnet/Salicnet/Salicnet.php 
Analisando a tabela 3 , constata-se que a totalidade dos editais, cujos recursos totais no valor de $\mathrm{R} \$ 1.808 .000,00$ (um miIhão e oitocentos e oito mil reais) são oriundos de renúncia fiscal (Lei Rouanet), atende aos objetivos, metas e à missão do CCC/RJ.

A missão do CCC/RJ está expressa em seus termos constitutivos e disponibilizada na página eletrônica do Centro.

Promover a inserção do indivíduo na sociedade através da cultura, da preparação profissional e do resgate da dignidade, de forma a contribuir para a melhoria da qualidade de vida dos menos favorecidos para a redução das desigualdades sociais, buscando sempre no exemplo de Cartola a referência para a construção da cidadania pela arte (CCC/RJ, 2014×x).
Voltando à análise da tabela 3 , verifica-se que, do volume total de recursos, $47,6 \%$ referem-se a um projeto de reestruturação das instalações do Centro, visando criar espaço para salas de aula e para implantação do Centro de Referência da Memória do Samba Carioca. Considerando que a melhoria da capacidade instalada pode se refletir na qualidade dos serviços oferecidos pelo CCC/RJ, o projeto em questão, também, está alinhado com as metas, objetivos e missão do Centro.

A terceira fonte de dados foi fornecida pelo CCC/RJ que disponibilizou material para levantamento sobre projetos financiados com recursos do Governo do Estado do Rio de Janeiro, por meio de suas Secretarias de Estado. Estes dados estão consolidados na tabela 4, onde são apresentadas as informações disponibilizadas.

\section{Tabela 4}

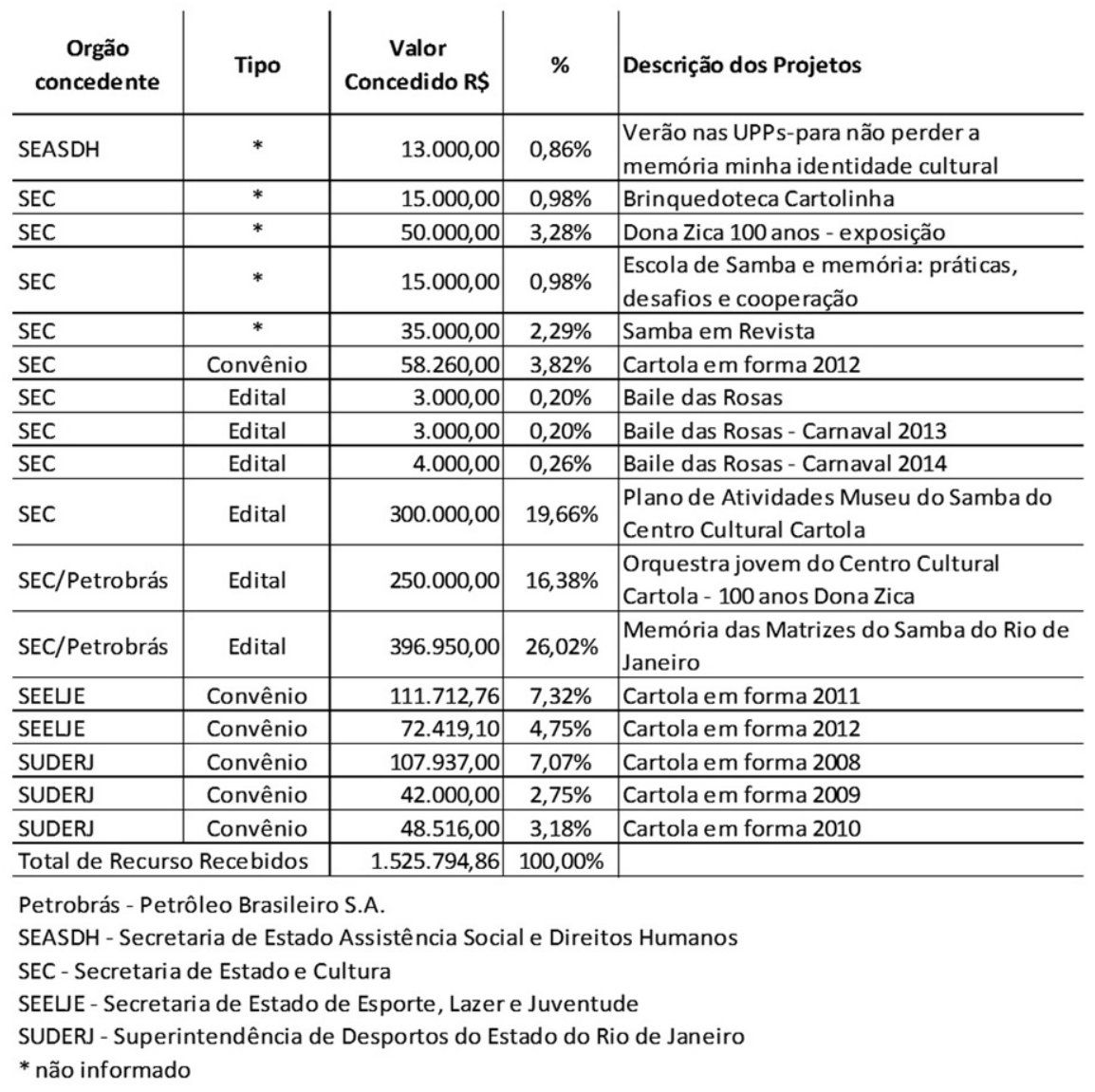

Fonte: Centro Cultural Cartola 
Analisando a tabela 4 , identifica-se que, do total de recursos captados pelo CCC/RJ, através de editais (63\%), o montante de $42,4 \%$ materializou-se por meio de renúncia fiscal concedida pelo Governo do Estado do Rio de Janeiro sobre a competência arrecadatória do Imposto sobre Circulação de Mercadorias e Prestação de Serviços (ICMS). A Petróleo Brasileiro S.A. (Petrobras), empresa beneficiada pela renúncia, destinou $\mathrm{R} \$ 646.950,00$ (seiscentos e quarenta e seis mil e novecentos e cinquenta reais) do benefício fiscal, decorrente do não recolhimento do ICMS, nos projetos Orquestra jovem do Centro Cultural Cartola - 100 anos Dona Zica e Memória das Matrizes do Samba do Rio de Janeiro.

1. Projeto Memória das Matrizes do Samba do Rio de Janeiro

O projeto específico escolhido para análise nesta pesquisa foi o denominado Memórias das Matrizes do Samba do Rio de Janeiro, que tinha como meta salvaguardar as produções das Matrizes do Samba no Rio de Janeiro, reconhecidas como Patrimônio Cultural do Brasil pelo IPHAN. O projeto foi escolhido pelos seguintes motivos: 1. vinculou tanto ações que fomentam a proposta de conformação do Museu do Samba Carioca (pesquisa, constituição de acervos, exposição) quanto ações de valorização de bens culturais imateriais - tendo inclusive sido enquadrado na linha de financiamento destinado a Patrimônio Imaterial; 2. foi financiado por meio de seleção pública gerida pela Petrobras.

A Petrobras é uma das principais instituições financiadoras de projetos culturais, por meio da isenção de ICMS e Mecenatoxi, apresentando um Programa específico de financiamento denominado Petrobras Cultu- ral. A instituição explica que financia projetos porque:

- Produz resultados sociais, ambientais, culturais e esportivos relevantes para o país, o que reafirma o papel estratégico da Petrobras como promotora de desenvolvimento sustentável - Potencializa a identificação dos brasileiros com a Petrobras

- Promove e fortalece a marca e a reputação da Companhia

[Destacando que] não implementa ou realiza a gestão direta de projetos sociais, ambientais, culturais ou esportivos, mas apóia, de forma planejada e monitorada, diversas iniciativas executadas por instituições públicas, privadas e de organizações não governamentais em todo o Brasil. ${ }^{x x i i}$

É frente a tais posicionamentos de financiadores que, como afirma Mendonça e Neco (2013), surgem críticas de alguns setores com o argumento de que esta forma de fomento à cultura custeada por dinheiro público (por meio de isenções fiscais), acaba por financiar, a reboque das políticas públicas de incentivo à cultura, o marketing das empresas patrocinadoras. Os projetos institucionais ou de pessoas físicas para serem executados passaram a precisar, além de aprovação dos pareceristas das diversas instâncias do Ministério da Cultura ou dos Governos Estaduais e Municipais, de gerenciamento capaz de apresentar potencial de autogestão, captação de recursos e valorização do marketing explorado pelos futuros patrocinadores - já que o governo deixa nas mãos dos patrocinadores a definição do que deve ser financiado.

O projeto analisado contemplava ações a serem concluídas ao longo de 12 meses, dentre as quais incluía pesquisa, tratamento e preservação de acervos, coleta de depoimentos com registro audiovisual, dentre outras, conforme quadro 1. 


\section{Quadro 1}

\begin{tabular}{|c|c|c|c|c|c|c|c|}
\hline \multirow{2}{*}{ Fases } & \multirow{2}{*}{$\begin{array}{c}\text { Descrição dos } \\
\text { Produtos }\end{array}$} & \multicolumn{2}{|c|}{ Prazo de execução } & \multirow{2}{*}{$\begin{array}{c}\text { Produto } \\
1\end{array}$} & \multirow{2}{*}{$\begin{array}{c}\text { Produto } \\
2\end{array}$} & \multirow{2}{*}{$\begin{array}{c}\text { Produto } \\
3\end{array}$} & \multirow{2}{*}{$\begin{array}{c}\text { Produto } \\
4\end{array}$} \\
\hline & & Início & Término & & & & \\
\hline 1 & $\begin{array}{l}\text { Tratamento } \\
\text { técnico do } \\
\text { acervo }\end{array}$ & $01 / 08 / 2013$ & $31 / 07 / 2014$ & & & & $x$ \\
\hline 2 & Site & $01 / 12 / 2013$ & $31 / 12 / 2013$ & $X$ & & & \\
\hline 3 & $\begin{array}{l}\text { Depoimentos - } \\
\text { produto } 1\end{array}$ & $11 / 11 / 2013$ & $10 / 01 / 2014$ & $x$ & & & \\
\hline 4 & $\begin{array}{l}\text { Depoimentos - } \\
\text { produto } 3\end{array}$ & $07 / 02 / 2014$ & $17 / 04 / 2014$ & & & $x$ & \\
\hline 5 & Revista & $03 / 02 / 2014$ & $30 / 04 / 2014$ & & $X$ & & \\
\hline 6 & Exposição & $01 / 12 / 2013$ & $31 / 07 / 2014$ & & & & $X$ \\
\hline
\end{tabular}

1 - Período de realização de aquisição do acervo

2 - Período de criação do website

3 - Período de realização de cinco depoimentos

4 - Período de realização de cinco depoimentos

5 - Período de elaboração e impressão da Revista Samba

6 - Período de realização da Exposição

Fonte: Centro Cultural Cartola

$\mathrm{Na}$ elaboração do projeto foram selecionados indicadores de acompanhamento quantitativos, em relação à proposta de tratamento técnico do acervo. Os indicadores eleitos tiveram por finalidade indicar, quantitativa- mente, as metas a serem alcançadas para serem comparadas com o que foi realizado. O quadro 2 apresenta alguns indicadores arbitrados para o acompanhamento da execução da fase de tratamento técnico do acervo. 


\section{Quadro 2}

\begin{tabular}{|l|l|c|c|}
\hline Objetivo & Objeto & Meta & Executado \\
\hline Catalogar & Livros & 530 & 530 \\
\hline Catalogar & Fotografias & 2.000 & 2.195 \\
\hline Digitalizar & Fotografias & 2.000 & 2.195 \\
\hline Catalogar & Recortes de jornais e revistas & 2.000 & 2.098 \\
\hline Digitalizar & Recortes de jornais e revistas & 2.000 & 2.098 \\
\hline Catalogar & Revistas & 500 & 500 \\
\hline Identificar & Indumentária & 7 & 7 \\
\hline Acondicionar & Indumentária & 7 & 7 \\
\hline Inventariar & Vídeo & 214 & 214 \\
\hline Inventariar & CDs & 308 & 334 \\
\hline Digitalizar & Fitas VHS & 62 & 62 \\
\hline Catalogar & Croquis & 118 & 118 \\
\hline Digitalizar & Croquis & 118 & 118 \\
\hline Catalogar & LPs & 112 \\
\hline Digitalizar & LPs & 112 \\
\hline & & 112 & \\
\hline
\end{tabular}

Fonte: $3^{\circ}$ Relatório Final de Atividades - Projeto: Memórias das Matrizes do Samba do Rio de Janeiro

Estes indicadores estão vinculados às estratégias e diretrizes apontadas no Plano Nacional Setorial de Museu para o período de 2010 a 2020, a exemplo: 1. Fomentar a pesquisa, o registro e a preservação das práticas socioculturais, valorizando a diversidade e a inclusão social em espaços como as universidades públicas, os museus e outras instituições vinculadas à memória; 2 . Ampliar a capacidade de atendimento educacional dos museus e oferecer condições permanentes para que as comunidades reconheçam os bens culturais materiais e imateriais de sua região, visando disseminar noções de identidade e zelo. ; 3. Fomentar as atividades de pesquisa e documentação que levem ao aprofundamento do discurso crítico e reflexivo sobre os acervos de museus; 4. Registrar os bens culturais materiais e imateriais, objeto da missão do museu.

Uma questão que se coloca em relação a indicadores de desempenho é que, em termos técnicos de avaliação, possuem estrei- ta racionalidade e similaridades como modelos de avaliação econômica (SIENA, 2002). Nesta linha, a literatura da área de negócios é vasta quando se trata de indicadores de desempenho (HOJI, 2014; PADOVEZE; TARANTO, 2009; SÁ, 2014; SILVA, 2010; SCHUBERT, 2005). No campo da área de negócios, os indicadores de desempenho, frequentemente, estão voltados para avaliação de resultados decorrentes de decisões de investimento, financiamento e de retorno operacional da empresa, com vista a maximizar o patrimônio ou oferecer mecanismos de proteção e acompanhamento das atividades empresariais envolvidas (HOJl, 2014; MATARAZZO, 2010; PADOVEZE; TARANTO, 2009; SILVA, 2010; SCHUBERT, 2005).

Esta linha adere ao conceito de sustentável sob a ótica econômica, que analisa o mundo em termos de estoques e fluxo de capital (RUTHERFORD, 1997). Entretanto, na área cultural, na qual se espera que os resultados sejam predominantemente sociais, as 
avaliações restritas ao domínio de conceitos econômicos e financeiros devem ser ponderadas, pois como afirma o IBRAM (2014:31)

No caso da economia da cultura, há uma clara necessidade de avançar nos pressupostos a serem considerados nessa abordagem de indicadores, em especial pelo fato de a cultura ser um fenômeno socialmente estabelecido que sofre influência tanto do valor econômico quanto do simbólico; logo, a determinação do indicador não pode estar descolada do contexto sociocultural em que se dá esse processo.

Analisando o Regulamento Geral da seleção pública da Petrobras (PETROBRAS, 2012), que rege a elaboração do edital voltado à linha de Patrimônio Imaterial, à qual está vinculado o projeto Memórias das Matrizes do Samba do Rio de Janeiro, foram encontradas regras de enquadramento condicionadas à habilitação e aprovação de projetos. Estas regras de enquadramento, propostas pelo
Regulamento, procuram atender às diretrizes legais para concessão de financiamento público a entidades da área da cultura e às propostas encaminhadas pelas Políticas Públicas Setoriais de Museu e de Patrimônio Imaterial que se propõem a legitimar as demandas das comunidades ${ }^{\text {xiii. }}$ Outras regras observadas no Regulamento Geral estão voltadas para resguardar o financiador (Petrobras) contra recursos interpostos pelos proponentes, além de medidas protetivas contra quaisquer ações judiciais relacionadas ao não cumprimento da legislação vigente do país, que possam vir a ser ignoradas pelo executor do projeto ${ }^{\text {xxiv }}$.

O Regulamento Geral define e torna públicas as regras gerais da seleção pública dos editais elaborados pelo financiado (PETROBRAS, 2012). Neste documento são relacionados alguns parâmetros que estão apresentados no quadro 3 , como os objetivos pretendidos para seleção e as diretrizes elaboradas em conformidade às propostas de concessão.

\section{Quadro 3}

\begin{tabular}{|c|c|}
\hline Parâmetros & Descrição \\
\hline Objetivos & $\begin{array}{l}\text { Selecionar projetos culturais que estejam em conformidade com este } \\
\text { regulamento e com os regulamentos especificos de cada linha e áreas definidas. } \\
\text { Selecionar projetos culturais em conformidade com as diretrizes. }\end{array}$ \\
\hline $\begin{array}{l}\text { Linhas de } \\
\text { atuação }\end{array}$ & $\begin{array}{l}\text { Preservação e Memória } \\
\text { Produção e Difusão }\end{array}$ \\
\hline $\begin{array}{l}\text { Setores } \\
\text { selecionados }\end{array}$ & $\begin{array}{l}\text { Preservação e Memória } \\
\text { - Apoio a museus, arquivos e bibliotecas } \\
\text { - Memória das artes } \\
\text { - Patrimônio imaterial } \\
\text { Produção e Difusão } \\
\text { - Circulação de exposições } \\
\text { - Manutenção de grupos e companhias de teatro } \\
\text { - Manutenção de grupos e companhias de dança } \\
\text { - Produção de filmes de longa-metragem para salas decinema } \\
\text { - Festivais de cinema } \\
\text { - Produção literária: ficção e poesia } \\
\text { - Apoio a artistas, grupos ou redes musicais } \\
\text { - Festivais de música }\end{array}$ \\
\hline
\end{tabular}




\begin{tabular}{|c|c|}
\hline $\begin{array}{l}\text { Condições } \\
\text { requeridas } \\
\text { para participar }\end{array}$ & $\begin{array}{l}\text { Estão aptas a se inscrever nesta seleção pública todas as pessoas jurídicas de } \\
\text { natureza cultural, com ou sem fins lucrativos. Com exceção para a área de } \\
\text { "Produção literária: ficção e poesia", na qual somente poderão se inscrever } \\
\text { pessoas físicas, e para a área de "Apoio a artistas, grupos e redes musicais", no } \\
\text { segmento das "Redes Musicais", em que somente são permitidas as inscrições } \\
\text { de pessoas jurídicas sem fins lucrativos. } \\
\text { As pessoas jurídicas deverão estar sob controle acionário, estatutário ou } \\
\text { majoritário de brasileiros natos, naturalizados ou de estrangeiros residentes no } \\
\text { Brasil há mais de } 3 \text { (três) anos, com idade mínima de } 18 \text { (dezoito) anos. } \\
\text { Deverão, ainda, se enquadrar em um dos formatos abaixo: } \\
\text { - ser de direito privado sem fins lucrativos: fundações particulares, ONGs, } \\
\text { associações, institutos etc. } \\
\text { - ser de direito privado com fins lucrativos: produtoras, empresas especializadas } \\
\text { na execução de projetos culturais etc. } \\
\text { - ser de direito público (da administração indireta): fundações e autarquias. } \\
\text { Obs.: As pessoas físicas deverão ser brasileiros natos, naturalizados ou anos. } \\
\text { estrangeiros residentes no Brasil há mais de } 3 \text { (três) anos, com idade mínima de } \\
\text { (18) }\end{array}$ \\
\hline $\begin{array}{l}\text { Condições } \\
\text { para não } \\
\text { participar da } \\
\text { seleção }\end{array}$ & $\begin{array}{l}\text { Integrantes da Triagem Administrativa, das Comissões de Análise Técnica, do } \\
\text { Conselho Petrobras Cultural e qualquer profissional envolvido na gestão do } \\
\text { Petrobras Cultural, bem como seus cônjuges, companheiros(as), filhos(as) e } \\
\text { enteados(as); } \\
\text { - Qualquer integrante da força de trabalho da Petrobras (empregado ativo ou } \\
\text { terceirizado, durante a vigência de seu contrato) edas suas subsidiárias; } \\
\text { - Pessoas jurídicas de direito público de administração direta (prefeituras } \\
\text { municipais, governos distrital ou estaduais e universidades estaduais ou } \\
\text { federais). } \\
\text { Obs.: O descumprimento de quaisquer destas condições implicaráa impugnação } \\
\text { do projeto em qualquer fase da seleção. }\end{array}$ \\
\hline $\begin{array}{l}\text { Exigências de } \\
\text { preenchimentc } \\
\text { de relatórios }\end{array}$ & $\begin{array}{l}\text { Preenchimento de Relatório relacionando as principais atividades do projeto } \\
\text { contidas no plano de trabalho, indicando os prazos de realização de cada uma } \\
\text { delas, devendo usar o mês como unidade. } \\
\text { Preenchimento do Relatório Físico-Financeiro nos moldes exigidos para a } \\
\text { inscrição na Lei Rouanet. A planilha com o orçamento deve conter também os } \\
\text { subtotais por etapa e o valor total do projeto. }\end{array}$ \\
\hline
\end{tabular}

Fonte: Petrobras, 2012 
No que tange à linha de atuação Preservação e Memória, especificamente, em relação ao setor de Patrimônio Imaterial, o Regulamento Específico frisa a importância de detalhar o valor histórico e cultural do patrimônio imaterial objeto do projeto e de que forma será garantido o acesso público aos seus resultados e qual o grau de participação das comuni- dades ou de pessoas detentoras do conhecimento a ser divulgado ou promovido no desenvolvimento do projeto (PETROBRAS, 2012). Em relação ao cumprimento desses indicadores de resultados, o $3^{\circ}$ Relatório Final de Atividades do projeto Memória das Matrizes do Samba do Rio de Janeiro, elaborado pelo CCC/RJ, apresenta os indicadores, conforme quadro 4.

\section{Quadro 4}

\begin{tabular}{|c|c|c|}
\hline Escola & Endereço & Participantes \\
\hline E. M. Nilo Peçanha & Avenida Pedro II, n³98. São Cristovão. & 290 \\
\hline E.M. Uruguai & Rua Ana Neri, $n^{\circ} 192$. Benfica & 502 \\
\hline E.M. Marechal Trompowsky & $\begin{array}{l}\text { Avenida Bartolomeu Gusmão, no 1.100. São } \\
\text { Cristóvão }\end{array}$ & 218 \\
\hline E.M. Cardeal Leme & Rua Ébano, 205 - Benfica & 1.407 \\
\hline FAETEC - Adolpho Bloch & $\begin{array}{l}\text { Avenida Bartolomeu de Gusmão, 850. São } \\
\text { Cristóvão }\end{array}$ & 469 \\
\hline E. M. Gonzaga da Gama Filho & Rua Gustavo Cordeiro de Farias, $n^{\circ} 578$. Benfica & 594 \\
\hline CIEP Nação Mangueirense & $\begin{array}{l}\text { Rua Santos Melo, nº73 Fundos. São Francisco } \\
\text { Xavier }\end{array}$ & 393 \\
\hline Escola Tia Neuma & Rua Santos Mello, 73 - São Francisco Xavier & 499 \\
\hline Escola Municipal Tia Ciata & Avenida Presidente Vargas $s / n$ & 141 \\
\hline \multicolumn{2}{|c|}{ Total de participantes beneficiados pelo projeto (alunos) } & 5.513 \\
\hline
\end{tabular}

Fonte: Centro Cultural Cartola

Estes indicadores de resultados apresentam o desempenho do projeto Memórias das Matrizes do Samba do Rio de Janeiro no que diz respeito à meta de retorno social de interesse da comunidade de sambistas e que possam se refletir nos resultados socioculturais e econômicos alcançados pelos projetos.Pela análise dos indicadores apresentados, observa-se que os mesmos são aderentes à proposta de trabalho (objetivos) do projeto e satisfazem a necessidade de acompanhamento da fase de execução.

Apesar da análise dos indicadores demonstrar efetivação com a valorização da diversidade cultural e retorno social aos estudantes e às comunidades sambistas, o problema esbarra em questões relacionadas à sustentabilidade do projeto e porque não dizer da instituição. Sobre isso, Hargreaves (2007) coloca que projetos carregam promessas e esperanças sendo, portanto, 
o maior desafio a questão da sustentabilidade. Sobre este tema, Park (1997, citado por BELLEN, 2006) afirma que os projetos sociais submetem-se à racionalidade econômica para tentar obter resultados capazes de garantir sua continuidade. Nesta mesma perspectiva, pode-se dizer que um dos grandes problemas, ao se pensar nos incentivos fiscais que viabilizam os patrocínios como modelo de financiamento da cultura, é que esse incentivo se tornou praticamente o todo e não uma das partes da política pública de financiamento da cultura. Hoje, até mesmo instituições consolidadas como Museus (configuração e enquadramento com os quais o Centro Cultural Cartola pretende se estabelecer a curto prazo, conforme será exposto no tópico abaixo) para manterem atividades básicas precisam se adequar a este modelo.

Porém, a adequação a esse modelo de financiamento não é um problema maior que a ausência de orçamentos próprios para aquelas instituições. Segundo dados do IBRAM $^{x \times v}$ (2011), a maioria das instituições museológicas cadastradas no Cadastro Nacional de Museus ${ }^{\text {xxi }}$ (a exemplo do Centro Cultural Cartola) encontram-se na condição de não apresentar orçamento próprio, denotando falta de autonomia sobre as ações que devem ser institucionalizadas por priorizarem o enquadramento de suas ações na conformação dada pelos editais disponibilizados por possíveis patrocinadores. Essas ações passam a ter obrigatoriamente que estar enquadradas nos indicadores de desempenho determinados pelos financiadores.

Ao se refletir sobre as questões relacionadas à ausência de orçamento e dos ingressos de recursos para financiamento das atividades, na modalidade mecenato, este quadro torna-se preocupante porque não se pode pensar, por exemplo, uma instituição museológica como um projeto, suas ações precisam de continuidade. No entanto, a ausência de um orçamento que reflita as es- tratégias de longo prazo quando conjugada a este modelo de financiamento fazem as instituições culturais trabalharem aos saltos.

\section{Conclusão}

A proposta deste estudo visa encontrar nos editais lançados, no Brasil, vinculação entre preservação de bens culturais e indicadores de desempenho alinhados a metas que visam à gestão e sustentabilidade. Tem como proposta analisar potencialidades e dificuldades encontradas pelo Centro Cultural Cartola/Museu do Samba Carioca para equalizar sua missão institucional ao atendimento das exigências para aprovação de projetos culturais e à comprovação das metas e indicadores alcançados, visando explicitar se os editais na prática aplicam as propostas encaminhadas pelas Políticas Públicas setoriais de Museu e de Patrimônio Imaterial que se propõem a legitimar as demandas das comunidades. Também pretende verificar se a configuração dos indicadores de desempenho apresentados nos editais é alinhada à meta de retorno social de interesse da comunidade de sambistas e se reflete os resultados socioculturais e econômicos alcançados pelos projetos.

Pelos resultados encontrados e atendendo às premissas eleitas neste trabalho, foram identificados alinhamentos entre os indicadores de desempenho e as propostas dos projetos executados pelo Centro Cultural Cartola, notadamente em relação às metas e aos resultados alcançados. Os resultados encontraram evidências sobre a aderência entre as metas elencadas nos projetos de financiamentos públicos e os objetivos sociais e culturais da proponente Centro Cultural Cartola/Rio de Janeiro (CCC/RJ).

Conforme dados retirados do Portal da Transparência, sumarizados na tabela 2, os convênios firmados com o Governo Federal apresentam metas aderentes 
aos objetivos do CCC/RJ. Majoritariamente (89,4\%), dos convênios foram firmados com Instituto do Patrimônio Histórico Artístico Nacional (IPHAN), órgão subordinado ao Ministério da Cultura. Em relação aos dados coletados do Sistema de Apoio às Leis de Incentivo à Cultura (SalicNet), quando se analisam as informações consolidadas na tabela 3, constata-se que a totalidade dos editais, cujos recursos são oriundos de renúncia fiscal (Lei Rouanet), atendem aos objetivos, metas e a missão do CCC/RJ.

Em relação aos recursos concedidos na esfera do Governo Estadual do Rio de Janeiro, os dados estão relacionados na tabela 4. Nesta modalidade de captação de recursos, verificou-se, também, que as linhas de financiamento estavam aderentes às metas e objetivos do CCC/RJ.

$\mathrm{Na}$ elaboração do projeto de salvaguarda das Matrizes do Samba no Rio de Janeiro foram identificados indicadores de desempenho voltados para avaliar os resultados alcançados pelo projeto. Neste caso, também, foram encontrada evidências de aderência entre os índices de desempenho exigidos nos editais, notadamente em relação ao acompanhamento dos resultados a serem alcançados e às metas de retorno social de interesse da comunidade de sambistas e se refletindo-se nos resultados socioculturais e econômicos alcançados pelos projetos.

Conforme exposto, os resultados encontrados nos editais, na prática, aplicam as propostas encaminhadas pelas Políticas Públicas setoriais de Museu e de Patrimônio Imaterial que se propõem a legitimar as demandas das comunidades. Dentro desta linha, observou-se que a configuração dos indicadores de desempenho apresentados nos editais, especificamente voltados para acompanhamento das metas eleitas e de resultados esperados, estava alinhada à meta de retorno social de interesse da comunidade de sambis- tas e reflete os resultados socioculturais e econômicos alcançados pelos projetos.

Nesta linha, pode-se dizer que existem potencialidades encontradas pelo Centro Cultural Cartola/Museu do Samba Carioca para equalizar sua missão institucional, o atendimento às exigências para aprovação de projetos culturais e a comprovação das metas e indicadores alcançados. Porém suas dificuldades são relativas à sustentabilidade econômica.

\section{Bibliografia:}

ARMANI, Domingos. Como elaborar projetos? Guia prático para elaboração e gestão de projetos sociais. Porto Alegre: Tomo Editorial, 2001.

BELLEN, Hans Michel Van. Indicadores de sustentabilidade: uma análise comparativa. Rio de Janeiro: FGV, 2006.

BRASIL (CF 88). Constituição da República Federativa do Brasil de 1988. Disponível em: <http:/l www.planalto.gov.br>. Acesso em 28/09/13.

CALABRE, Lia. Políticas culturais no Brasil: balanço e perspectivas. In: RUBIM, Antonio A. C. (org.). Politicas culturais no Brasil. Salvador: EDUFBA, 2007. Disponível em https://repositorio.ufba.br/ri/ bitstream/ufba/138/1/Politicas\%20culturais.pdf. Acesso em 01/07/2013.

GIL, Antonio Carlos. Como elaborar projetos de pesquisa. São Paulo: Atlas, 2010.

HANSON, Denis. Gestão e Cultura: Um panorama dos argumentos pró e contra. In: III SEGeT - Simpósio de Excelência em Gestão e Tecnologia. Rio de Janeiro, 2006.

HARGREAVES, Andy. Liderança sustentável: desenvolvendo gestores da aprendizagem. Porto Alegre: Artmed, 2007.

HOJI, Masakazu. Administração financeira orçamentária. São Paulo: Atlas, 2014.

IBGE - INSTITUTO BRASILEIRO DE GEOGRAFIA E ESTATÍSTICA. Sistema de informação e in- 
dicadores culturais. Estudos e Pesquisas: Informações demográficas e socioeconômica, n. 22, 2007.

IBRAM - INSTITUTO BRASILEIRO DE MUSEUS. Museus em números. Brasília: IBRAM, 2011.

IBRAM - INSTITUTO BRASILEIRO DE MUSEUS. Museus e a dimensão econômica: da cadeia produtiva à gestão sustentável. Brasília, DF: Ibram, 2014. (Coleção Museu, Economia e Sustentabilidade, 2). Disponível em http://www.museus.gov.br/wp-content/uploads/2015/01/Museus_DimensaoEconomica_Ibram2014.pdf. Acesso em 01/03/2015.

IPHAN - INSTITUTO HISTÓRICO E ARTÍSTICO NACIONAL. Dossiê das Matrizes do Samba no Rio de Janeiro: Partido-alto, Samba de terreiro e Samba-enredo. Brasília, DF: Departamento de Patrimônio Imaterial / Iphan, 2006.

MARCONI, Marina de Andrade ; LAKATOS, Eva Maria. Metodologia do trabalho científico. São Paulo: Atlas, 2011.

MENDONÇA, Elizabete de Castro ; NECO, Luis Antônio do Nascimento. Cultura y gestión, una relaciónencrecimiento: el impacto enlaformación de los gestores culturales. In: PAIS ANDRADE, Marcela Alejandra ; MOLINA ROLDÁN, Ahtziri (org.). Cultura y desarrollo em América Latina: actores, estrategias, formación y prácticas. 1ed. Buenos Aires: Cooperativas, v. 1, 2013. p. 109-130.

NOGUEIRA, Nilcemar. A patrimonialização do samba. In: MENDONÇA, Elizabete de Castro ; SILVA, Júnia Gomes da Costa Guimarães e (org.). Bens culturais musealizados: políticas públicas, preservação e gestão. Rio de Janeiro: UNIRIO / Escola de Museologia, 2014. p. 33-44.

PADOVEZE, Clóvis Luís; TARANTO, Fernando Cesar. Orçamento empresarial: novos conceitos e técnicas. São Paulo: Pearson, 2009.

SÁ, Carlos Alexandre. Orçamento empresarial: novas técnicas de elaboração e de acompanhamento. São Paulo: Atlas, 2014.

SARTOR, Carla Daniel. As políticas públicas culturais e a perspectiva da transformação: a experiência coletiva nos Pontos de Cultura. Tese (Doutorado em Serviço Social). Programa de Pós-Graduação em Serviço Social. Rio de Janeiro: Pontifícia Universidade Católica do Rio de Janeiro, 2011.

SCHUBERT, Pedro. Orçamento empresarial integrado: metodologia, elaboração, controle e acompanhamento. Rio de Janeiro: Freitas Basto, 2005.
SIENA, Osmar. Método para avaliar o progresso em direção ao desenvolvimento sustentável. Tese (Doutorado em Engenharia de Produção). Programa de Pós-Graduação em Engenharia de Produção. Florianópolis:.Universidade Federal de Santa Catarina, 2001.

SILVA, José Pereira. Análise financeira das empresas. São Paulo: Atlas, 2010.

THIRY-CHERQUES, Hermano Roberto. Projetos culturais: técnicas de modelagem. Rio de Janeiro: FGV, 2008.

\section{Sites}

http://portal.jphan.gov.br

http://fatosedados.blogspetrobras.com.br/wp-content/uploads/2009/06/patrocinios-petrobras1.pdf

http://sistemas.cultura.gov.br/salicnet/Salicnet/Salicnet.php

http://www.portaltransparencia.gov.br/

http://www.cartola.org.br/apresentacao.html

http://ppc.petrobras.com.br/wp-content/uploads/2011/11/PETROBRAS-CULTURAL-2012-Regulamento-GERAL6.pdf

\section{Recebido em 11/08/2015 Aprovado em 24/08/2015}

\footnotetext{
i Elizabete de Castro Mendonça, Universidade Federal do Rio de Janeiro, Brasil. Contato: elizabete.mendonca@unirio.br
}

Graduação em Museologia, doutorado em Artes Visuais. Professora do Departamento de Estudos e Processos Museológicos e do Programa de Pós-Graduação em Museologia e Patrimônio da Universidade Federal do Estado do Rio de Janeiro (UNIRIO). Atua também no Programa de Pós-Graduação em Arqueologia da Universidade Federal de Sergipe. É líder do Grupo de Estudo e Pesquisa do CNPq em Mseologia, Conhecimentos Tradicionais e Ação Social (GEMCTAS).

ii Luís Antônio do Nascimento Neco, Universidade Federal do Rio de Janeiro, Brasil. Contato: luis.neco@facc.ufrj.br 
Graduação em Ciências Contábeis, especialização em Ciências Contábeis e em Gestão Financeira, Controladoria e Auditoria e mestrado em Ciências Contábeis. Professor do Departamento de Ciências Contábeis da Universidade Federal do Rio de Janeiro (UFRJ).

iii Nilcemar Nogueira, Centro Cultural cartola, Brasil. Contato: nilcemar.nogueira@gmail.com

Mestrado em Bens Culturais e Projetos Sociais, doutorado em Psicologia Social. Diretora Executiva do Centro Cultural Cartola e coordenadora do Programa de Salvaguarda do Samba Carioca.

iv "O Plano Nacional de Cultura (PNC), relativo ao período de 2010 a 2020 é instituído pela Lei 12.343, de 2 de dezembro de 2010 , tem por finalidade o planejamento e implementação de políticas públicas de longo prazo (até 2020) voltadas à proteção e promoção da diversidade cultural brasileira. Diversidade que se expressa em práticas, serviços e bens artísticos e culturais determinantes para o exercício da cidadania, a expressão simbólica e o desenvolvimento socioeconômico do País.

Os objetivos do PNC são o fortalecimento institucional e definição de políticas públicas que assegurem o direito constitucional à cultura; a proteção e promoção do patrimônio e da diversidade étnica, artística e cultural; a ampliação do acesso à produção e fruição da cultura em todo o território; a inserção da cultura em modelos sustentáveis de desenvolvimento socioeconômico e o estabelecimento de um sistema público e participativo de gestão, acompanhamento e avaliação das políticas culturais". (http://www. cultura.gov.br/plano-nacional-de-cultura-pnc-).

v Entre as instituições contratantes de projetos podemos citar, entre outras, Petrobras, Caixa Econômica Federal, Banco Nacional de Desenvolvimento (BNDES) e Banco do Brasil.

vi Em especial desde a década de 1990 existem, no mercado, profissionais direcionados especificamente para tal fim, tendo inclusive autores como Evrard e Colbert, citados por Hanson (2006), que consideram a gestão cultural como uma nova disciplina da gestão tradicional ou mesmo como um novo ramo independente. Gestão cultural entendida como atuação que envolve planejamento, organização, coordenação e controle (operacional, financeiro, administrativo e de desempenho) visando dirigir um programa, projeto ou ação de cunho cultural, podendo estes ser de curto ou longo prazo.

Nesta mesma perspectiva Mendonça e $\operatorname{Neco}$ (2013, p. 119), ao analisarem os dados presentes no SalicNet, afirmam "encontramos también un desequilibrio entre el número de proyectos presentados, aprobados y apoyados a través de patronato, así como la cantidad de corte hecho en montos aprobados. Estos datos demuestran la dificultad entre la aprobación y la ejecución de los proyectos. Teniendo en cuenta que nos hace preguntarnos si los proponentes (gestores culturales) tener conocimientos adecuados para tales fines presupuestarios y comprender el lenguaje técnico de la negociación de los proyectos junto a los patrocinadores. Es precisamente para cubrir este déficit que la figura de los gestores culturales obtiene (desde el 1990) demanda en el mercado, haciéndose más importantes en la recaudación de fondos y proyectos productivos. Ahora tienen que tener dominio sobre la redacción y aprobación de los proyectos, además de buscar inversiones de las empresas".

vii A observação dessas dificuldades abriu prerrogativas de interesse público em debate de forma mais ativa, democrática e permanente para proposições de políticas públicas que tinham como foco a formação de gestores qualificados (inclusive nos próprios grupos que detêm os conhecimentos a serem difundidos) para atuarem na área cultural - auxiliando, assim, na formação de gestores culturais que conjuguem as dimensões culturais, de políticas de preservação dos saberes associados e de sustentabilidade.

Em relação especificamente à sustentabilidade citada acima, foram elaboradas recomendações, textos-bases, consultas públicas, editais, decretos e leis que preconizam que os projetos devem se pautar na perspectiva da cultura com um bem que tem potencial para gerar trabalho, emprego e renda, além de propiciar oportunidades de inclusão social.

No entanto, como demonstra Sartor (2011) ao abordar Pontos de Cultura, tanto no que se refere à formação de gestores culturais quanto à sustentabilidade das ações e instituições, os processos não são tão rápidos e fáceis para se configurem em um projeto. É sim uma ação de política pública com investimentos em longo prazo.

Outro ponto de observação, como aborda Mendonça e Neco (2013, p. 110), é que, apesar do acentuado aumento de investimento em cultura em diferentes regiões do país, via incentivos federais, "se observa que este crecimiento no se ha adherido a la meta establecida por el Ministerio de Cultura (MinC) de gobiernos Lula y Dilma Rousseff, de dedicar mayores recursos a las regiones del país menos favorecidos em la distribución de fondos, dada la política de descentralización de la producción cultural en el país. Estosdatos pueden ser verificados por análisis el porcentaje en volumen de recursos entre lãs regiones. [...] la gestión de los recursos culturales se concentra en eleje sur este del país. Local, que durante décadas ha sido centralizada a la industria cultural y consecutivamente la formación de profesionales para actuar como gestores culturales".

viii No Brasil, o recurso destinado â cultura não atinge nem $1 \%$ do orçamento nacional. Em relação aos últimos anos, pode-se dizer queo orçamento da pasta cresceu sete anos seguidos entre 2003 e 2010, mas teve uma redução no governo de Dilma Rousseff. (MENDONÇA, NECO, 2013, p. 107)

ix É um dos mecanismos instituído pelo PRONAC que possibilita investimento em projetos culturais mediante doações e patrocínios. Permite abatimento do valor investido no imposto de renda devido pelo investidor na ordem de $6 \%$ para contribuinte pessoa física e $4 \%$ para pessoa jurídica. Devido aos problemas criados por esta forma de incentivo fiscal a lei que a institui, conhecida 
também por Lei Rouanet, está em fase de reformulação. As propostas de alteração causaram um embate entre os defensores de o governo voltar a ter uma maior autonomia e influência na definição do que deve ser financiado e os profissionais já consolidados pela antiga lei.

$x$ O Fundo Nacional de Cultura (FNC) também é um mecanismo instituído pelo PRONAC, porém apoia a fundo perdido projetos de entidades públicas e privadas sem fins lucrativos. Os proponentes são contemplados por meio de Editais.

xi Na prática o Fundo de Investimento Cultural e Artístico (Ficart) não foi estabelecido.

xii Ponto de Cultura, um eixo estruturante do Programa Cultura Viva, do Ministério da Cultura, é criado para "estimular os pontos vitais de expressão da cultura brasileira, por meio de recursos que potencializassem suas ações e dinamizassem sua comunicação". Este Programa está inserido dentro de uma proposta de reformulação do papel do Estado nas políticas públicas vinculadas à área de cultura que estabeleceu novos parâmetros de gestão e democracia na relação entre Estado e sociedade orientados pela articulação dos conceitos de empoderamento, autonomia e protagonismo social (SARTOR, 2011, p. 102-103).

xiii As "Matrizes do Samba no Rio de Janeiro: partido-alto, samba de terreiro e samba-enredo" foram registradas como Patrimônio Imaterial brasileiro no ano de 2007, sendo inscritas no Livro de Registro de Formas de Expressão.

xiv O Centro Cultural Cartola passou de Ponto à Pontão de Cultura Memória do Samba Carioca no âmbito do Plano de Salvaguarda das Matrizes do Samba no Rio de Janeiro, tendo sido este um dos bens indicados pelo IPHAN para tal fim. "O Pontão de Cultura é considerado o instrumento de promoção do intercâmbio e difusão cultural, baseados na articulação de Pontos de Cultura em rede e no apoio a iniciativas que integrem as diferentes linguagens e expressões artísticas. Os Pontões de Cultura são, entre outras ações, responsáveis por: a) a capacitação e formação dos agentes de cultura vinculados aos Pontos de Cultura; b) a criação e apresentação de obras artísticas realizadas em conjunto por dois ou mais Pontos de Cultura; c) a criação de mecanismos de distribuição, comercialização e difusão dos produtos culturais produzidos pelos Pontos de Cultura; d) a organização de festivais, encontros, fóruns e atividades correlatas que promovam o encontro, a troca de experiências e articulação entre Pontos de Cultura" (SARTOR, 2011, 115). No caso específico do CCC, o Pontão articula ações para as comunidades sambistas do Rio de Janeiro.

xv Disponível em: http://portal.iphan.gov.br

xvi Petróleo Brasileiro S.A. (Petrobras) é uma empresa de capital aberto (sociedade anônima), cujo acionista majoritário é o Governo do Brasil (União). Sendo, portanto, uma empresa estatal de economia mista. xvii O Portal da Transparência do Governo Federal é uma iniciativa da Controladoria-Geral da União (CGU), lançada em novembro de 2004, para assegurar a boa e correta aplicação dos recursos públicos. O objetivo é aumentar a transparência da gestão pública, permitindo que o cidadão acompanhe como o dinheiro público está sendo utilizado e ajude a fiscalizar.

xviii Trata-se de ferramenta sistêmica, gerenciada pelo Ministério da Cultura, para acessar e tratar informações sobre propostas culturais e projetos beneficiados pela Lei Rouanet. http://sistemas.cultura.gov.br/salicnet/Salicnet/Salicnet.php

\section{xix http://www.cartola.org.br/apresentacao.html}

xx http://www.cartola.org.br/missao.html

xxi "A Petrobras até 2012 destinou $\mathrm{R} \$ 380,70$ milhões para as seleções públicas do Petrobras Cultural. Este recurso foi repassado através de 91 seleções públicas lançadas em oito edições do programa. O Petrobras Cultural recebeu 30.777 inscrições e contemplou 1.452 projetos". (http://ppc.petrobras.com.br/edicoes-anteriores/)

xxii http://fatosedados.blogspetrobras.com.br/wp-content/uploads/2009/06/patrocinios-petrobras1.pdf

xxiii Para o enquadramento dos projetos nesta Área de Seleção Pública serão adotados, como referência, os conceitos presentes na legislação brasileira- Decreto n 3.551/2000 - e na Convenção da Unesco para a Salvaguarda do Patrimônio Cultural Imaterial, 2003. http:// ppc.petrobras.com.br/wp-content/uploads/2011/11/PETROBRAS-CULTURAL-2012-Regulamento-GERAL6. pdf. Acesso em 09 abr. 2015.

xxiv Quaisquer ônus por questões de direitos autorais recairão, exclusivamente, sobre o responsável pelo projeto. Petrobras Cultural - edição 2012 - Regulamento Geral de seleção pública. http://ppc.petrobras.com.br/ wp-content/uploads/2011/11/PETROBRAS-CULTURAL-2012-Regulamento-GERAL6.pdf - acesso em 0904-2015.

xxv O Instituto Brasileiro de Museus (IBRAM) é uma autarquia vinculada ao Ministério da Cultura, criada mediante a Lei n. ${ }^{\circ} 11.906$, de 20 de janeiro de 2009, que desmembrou do Instituto do Patrimônio Histórico e Artístico Nacional (IPHAN) a Diretoria de Museus e as Unidades Museológicas.

xxvi O Cadastro Nacional de Museus é um instrumento do Sistema Brasileiro de Museus(SBM) criado com o objetivo de conhecer e integrar o universo museal brasileiro. O Sistema Brasileiro de Museus, criado pelo Decreto $n^{\circ} 5.264$, de 5 de novembro de 2004, tem por finalidade facilitar o diálogo entre museus e instituições afins, objetivando a gestão integrada e o desenvolvimento dos museus, acervos e processos museológicos brasileiros. 